\title{
Intensitas Penggunaan Smartphone Dalam Dunia Pendidikan Kedinasan Terhadap Perilaku Komunikasi
}

\author{
Fiqih Bagus Aryo Seno \\ Progam Studi Manajemen Pemasyarakatan, Politeknik Ilmu Pemasyarakatan \\ Email: Fiqihbagus8@gmail.com
}

\begin{abstract}
ABSTRAK
Smartphone adalah media baru dalam hal proses komunikasi, salah satu jenis gadget ini memiliki banyak sekali manfaat yang besar dalam kehidupan. Tidak hanya digunakan untuk saling berkomunikasi, nyatanya smartphone juga memiliki fungsi yang sangat luas. Beberapa sekolah tinggi kedinasan memang mempunyai peraturan larangan Tarunanya menggunakan smartphone, tetapi Politeknik Ilmu Pemasyarakatan yang merupakan sekolah tinggi kedinasan dibawah naungan Kementerian Hukum dan Ham mempunyai aturan penggunaan smartphone untuk berkomunikasi dalam proses pembelajaran, pelatihan dan pengasuhan. Penelitian ini menggunakan satu variable independen (X) yaitu intensitas penggunaan smartphone dan satu variable dependen $(\mathrm{Y})$ yaitu perilaku komunikasi. Data primer dikumpulkan melalui metode survey terhadap 100 responden dengan menggunakan pendekatan insedental sampling. Teori yang digunakan diantaranya teori komunikasi, teori new media, psikologi komunikasi dan teori ketergantungan. Hasil penelitian menunjukan bahwa intensitas penggunaan smartphone berpengaruh signifikan terhadap perilaku komunikasi sebesar 69\% dan sisanya $31 \%$ dipengaruhi oleh faktor lain yang tidak terdapat dalam penelitian.
\end{abstract}

Kata Kunci: Intensitas, Smartphone, Kedinasan, Perilaku Komunikasi

\section{ABSTRACT}

Smartphones are a new medium in terms of the communication process, this type of gadget has many great benefits in life. Not only used to communicate with each other, in fact smartphones also have a very wide range of functions. Some official high schools do have regulations prohibiting cadets from using smartphones, but Correctional Science Polytechnic which is an official high school under the auspices of the Ministry of Law and Human Rights has rules on the use of smartphones to communicate in the learning, training and parenting process. This study uses one independent variable $(X)$, namely the intensity of smartphone use and one dependent variable (Y), namely communication behavior. Primary data were collected through a survey method of 100 respondents using an incedental sampling approach. The theories used include communication theory, new media theory, communication psychology and dependency theory. The results showed that the intensity of smartphone use had a significant effect on communication behavior by $69 \%$ and the remaining $31 \%$ was influenced by other factors not included in the study.

Keywords: Intensity, Smartphone, Officials, Communication Behavior 


\section{PENDAhuluan}

Dewasa ini pengguna smartphone di Indonesia terus meningkat dari waktu ke waktu. Sebuah lembaga riset menyebutkan bahwa Indonesia berada di peringkat kelima daftar pengguna smartphone terbesar di dunia. Data tersebut dilansir oleh Horace $\mathrm{H}$. Dediu melalui blognya, asymco.com. pada laman detik.com tertulis jika populasi Android telah mencapai lebih dari 1 milliar, sedangkan iOS mencapai 700 juta.

Temuan senada dengan hasil studi serupa dilaporkan oleh Asosiasi Penyedia Jasa Internet Indonesia (APJII) menunjukkan, rata-rata penggunaan internet oleh masyarakat Indonesia adalah 1-3 jam dalam sehari. Adapun persentasenya mencapai 43,89 persen Sementara itu, ada pula pengguna yang mengakses internet selama 4-7 jam dalam sehari dengan persentasenya mencapai 29,63 persen dan sebanyak 26,48 persen pengguna internet di Indonesia juga mengakses internet lebih dari 7 jam sehari.

Hal ini tentu menjadi factor penentu berubahnya perilaku individu dalam kegiatan sehari-hari khususnya dalam berkomunikasi terhadap individu lain karena perilaku komunikasi menetapkan siapa bicara dengan siapa, tentang apa, dan bagaimana. Perubahan mengenai perilaku individu dapat dipengaruhi salah satunya oleh lingkungan. Untuk menghindari perubahan perilaku ke arah yang buruk, seseorang harus dapat memosisikan diri dalam suatu lingkungan di era yang kini serba canggih akan teknologi.
Pada kenyataannya, pengguna smartphone memang sangat meme-ngaruhi perilaku komunikasi individu. Kini smartphone sudah menjadi media komunikasi yang pokok. Hal tersebut bisa dibuktikan dengan kenyataan dilapangan. Semua orang pasti tidak bisa lepas dari gadget, baik dalam berkomunikasi ataupun hanya sekedar mencari informasi melalui platform youtube. Hal ini menunjukan bahwa intensitas penggunaan smartphone berpengaruh terhadap perilaku individu

Oleh karena itu Politeknik Ilmu Pemasyarakatan yang merupakan Perguruan Tinggi Kedinasan dibawah Kementerian Hukum dan Hak Asasi Manusia melalui keputusan Direktur Politeknik Ilmu Pemasyarakatan memberlakukan penggunaan smartphone untuk taruna. Yang dirasa keputusan tersebut diharapkan dapat menjadi perubahan ke era yang lebih modern pada proses pengajaran, pelatihan dan pengasuhan pada Taruna Politeknik Ilmu Pemasyarakatan. Memang pada umumnya Dunia Pendidikan Kedinasan adalah kehidupan yang dimana mahasiswanya memiliki rutinitas yang padat, serta tuntutan yang tinggi, mulai dari tuntutan akademis, lingkungan asrama, hubungan senior - junior, dan sosial budaya; serta tekanan yang berbeda dengan mahasiswa pada umumnya. Permasalahan yang terjadi pada mahasiswa kedinasan ialah adanya peraturan dilarang menggunakan gadget/smartphone, hal ini yang menjadi dilema karena sulit jika para mahasiswa ingin berkomunikasi, ditambah lagi dengan kesulitan mengikuti perkembangan zaman yang sudah semakin canggih. 
Hal ini perlu diuji menggunakan beberapa teori diantaranya teori komunikasi yang berkaitan dengan proses komunikasi beberapa individu, teori new media yang terkait dengan media yang digunakan oleh individu dalam berkomunikasi, dan teori terpaan media yang menyangkut penggunaan media dalam berkomunikasi yang fokus pada frekuensi, durasi, Selain itu, digunakan pula teori psikologi komunikasi yang melihat perubahan psikologi individu dalam berkomunikasi menggunakan media, dan teori ketergantungan yang melihat ketergantungan sikap individu tersebut setelah menggunakan media dalam berkomunikasi.

Berdasarkan latar belakang masalah diatas, penulis mengidentifikasi beberapa masalah sebagai berikut:

1. Seberapa besar intensitas penggunaan smartphone di kalangan Taruna Politeknik Ilmu Pemasyarakatan?

2. Bagaimana manfaat perilaku komunikasi pengguna smartphone dikalangan Taruna Politeknik Ilmu Pemasyarakatan?

3. Seberapa besar pengaruh intensitas penggunaan smartphone terhadap perilaku komunikasi di kalangan Taruna Politeknik Ilmu Pemasyarakatan?

Penelitian ini bertujuan untuk mengetahui dan menganalisis intensitas penggunaan smartphone, menganalisis perilaku komunikasi pengguna smartphone, dan mengetahui pengaruh intensitas penggunaan Smartphone terhadap perilaku komunikasi di kalangan Taruna Politeknik ilmu Pemasyarakatan.

Komunikasi adalah proses penyampaian pikiran atau perasaan oleh seseorang kepada orang lain dengan menggunakan lambang-lambang yang bermakna bagi kedua pihak, dalam situasi yang tertentu komunikasi menggunakan media tertentu untuk merubah sikap atau tingkah laku seorang atau sejumlah orang sehingga ada efek tertentu yang diharapkan (Effendy, 2000: 13)

\section{TINJAUAN PUSTAKA}

Media baru atau new media merupakan istilah yang dipakai untuk semua bentuk media komunikasi massa yang berbasis teknologi komunikasi dan informasi. Media baru yang memiliki ciri tersebut adalah internet. Internet adalah jaringan kabel dan telepon satelit yang menghubungkan komputer (Vivian, 2008)

Menurut Khoirunnisa (2014), new media atau media baru mengaplikasikan teknologi Web 2.0 yang sangat mendukung perkembangan media sehingga banyak media lama yang melakukan transformasi menuju media baru.

\section{Psikologi komunikasi}

Psikologi komunikasi diartikan sebagai ilmu yang berusaha menguraikan, meramalkan, dan mengontrol peristiwa mental dan behavioral. Psikologi digunakan untuk mendukung tercapainya komunikasi yang efektif dan efisien. Kegagalan komunikasi dapat terjadi bila pesan yang dikomunikasikan tidak diterima secara cermat. Psikologi memiliki empat pendekatan yang dominan, di antaranya psikoanalisis, behaviorisme, psikologi kognitif, dan psikologi humanis. 


\section{Teori ketergantungan}

Teori ketergantungan adalah teori tentang komunikasi massa yang menyatakan bahwa ketika seseorang semakin bergantung pada suatu media untuk memenuhi kebutuhannya, media tersebut menjadi semakin penting untuk orang itu (Saverin and Tankard, 1992). Teori ini diperkenalkan oleh Sandra Ball-Rokeach dan Melvin Defleur. Mereka memperkenalkan model yang menunjukkan hubungan integral tak terpisahkan antara pemirsa, media, dan sistem sosial yang besar.
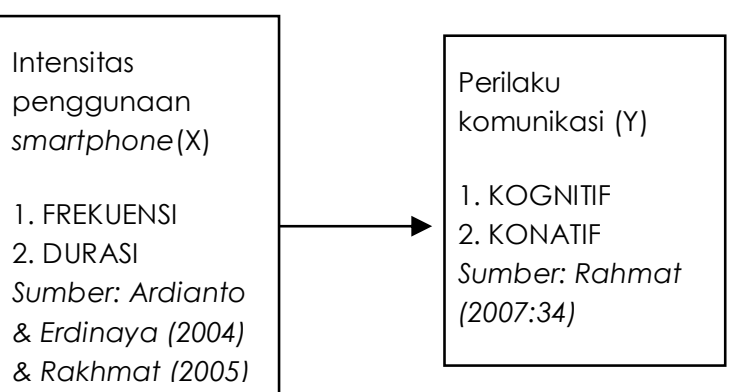

Gambar 1. Kerangka Penelitian

Dari kerangka penelitian yang dibuat, dapat terlihat bahwa terdapat subvariabel di antaranya frekuensi dan durasi. Variabel tersebut merupakan variabel $\mathrm{X}$ yaitu intensitas penggunaan smartphone yang dapat memengaruhi variabel $\mathrm{Y}$ yaitu perilaku komunikasi yang di dalamnya terdapat subvariabel di antaranya kognitif dan konatif.

\section{METODE}

Penelitian ini menggunakan metode deskriptif. Untuk penelitian lebih lanjut, analisis dilakukan dengan menggunakan metode analisis kuantitatif. Populasi penelitian adalah Taruna Politeknik Ilmu Pemasyarakatan yang menggunakan smartphone.

Jumlah populasi Taruna Politeknik Ilmu Pemasyarakatan sebanyak 1001 yang terdiri dari Taruna tingkat 1, tingkat 2, tingkat 3, dan tingkat 4. Sehingga sampel yang diperlukan sebesar 100 orang. Skor kuesioner yang diberikan kepada setiap responden. Dapat dilihat pada Tabel 1.

\section{Tabel 1. Skor Kuesioner}

\begin{tabular}{|l|l|c|}
\hline NO. & KETERANGAN & SKOR \\
\hline 1. & Sangat Setuju (SS) & 5 \\
\hline 2. & Setuju (S) & 4 \\
\hline 3. & Cukup (c) & 3 \\
\hline 4. & Tidak Setuju (ST) & 2 \\
\hline 5. & Sangat Tidak Setuju (STS) & 1 \\
\hline
\end{tabular}

\section{ANALISIS DATA}

Tabel 2

Operasinalisasi Variable Penelitian

\begin{tabular}{|c|c|c|}
\hline Variable & Indikator & Alat Ukur \\
\hline $\begin{array}{c}(\mathrm{X}) \\
\text { Intensitas } \\
\text { Penggunaan } \\
\text { Smartphone }\end{array}$ & - Durasi & $\begin{array}{l}\text { - Seberapa lama } \\
\text { Taruna } \\
\text { Menggunakan } \\
\text { Smartphone } \\
\text { - Seberapa } \\
\text { tinggi tingkat } \\
\text { keseringan } \\
\text { penggunaan } \\
\text { Smartphone }\end{array}$ \\
\hline $\begin{array}{l}\text { (Y) Perilaku } \\
\text { komunikasi }\end{array}$ & $\begin{array}{l}\text { - Kognitif } \\
\text { - Konatif }\end{array}$ & $\begin{array}{l}\text { - Kebermanfaat } \\
\text { an dari } \\
\text { Penggunaan } \\
\text { Smartphone } \\
\text { - Smartphone } \\
\text { Menjadi } \\
\text { Kebutuhan } \\
\text { yang penting }\end{array}$ \\
\hline
\end{tabular}




\section{Uji Validitas}

Valid berarti instrument tersebut dapat digunakan untuk mengukur apa yang hendak diukur (Sugiyono, 2009). Dalam uji validitas dapat digunakan rumus teknik korelasi product moment. Menurut Umar (2008)

$$
r_{x y}=\frac{n \sum x y-\sum x \sum y}{\sqrt{\left(n \sum x^{2}-\left(\sum x\right)^{2}\right)\left(n \sum y^{2}-\left(\sum y\right)^{2}\right)}}
$$

sebesar 0,1966. Merujuk pada hasil Uji validitas dihasilkan bahwa semua instrument mulai dari variable Intensitas penggunaan Smartphone (X) yang terdiri dari X1-X5 semuanya menghasilkan nilai (rHitung) > saripada rTable. Selain itu variable perilaku komunikasi (Y) yang terdiri dari Y1-Y5 semuanya menghasilkan nilai (rHitung) > dari pada rTabel. Sehingga dapat di pastikan bahwa semua instrument dalam penelitian ini dikatakan valid.

\section{Uji reabilitas}

Dalam uji reabilitas, kriteria suatu instrument dapat dikatakan reliable, jika hasil uji hitung $>0,6$, adapun untuk menguji reliabilitas instrumennya dengan menggunakan rumus Crobach's Alpha. Karena penelitian yang dilakukan berbentuk kuisioner.

Table 3.

Validasi Variable X (Intesitas penggunaan Smartphone) dan $Y$ (Perilaku Komunikasi)

\begin{tabular}{|ccccc|}
\hline $\begin{array}{c}\text { No } \\
\text { item }\end{array}$ & RHitung & $\begin{array}{c}\text { rTable } \\
\mathbf{5 \%} \\
\mathbf{( 9 8 )}\end{array}$ & Sig. & Kriteria \\
\hline X1 & 0,723 & 0,1966 & 0.000 & Valid \\
\hline X2 & 0,704 & 0,1966 & 0.000 & Valid \\
\hline X3 & 0,763 & 0,1966 & 0.000 & Valid \\
\hline X4 & 0,375 & 0,1966 & 0.000 & Valid \\
\hline X5 & 0,702 & 0,1966 & 0.000 & Valid \\
\hline Y1 & 0,809 & 0,1966 & 0.000 & Valid \\
\hline Y2 & 0,809 & 0,1966 & 0.000 & Valid \\
\hline Y3 & 0,626 & 0,1966 & 0.000 & Valid \\
\hline Y4 & 0,682 & 0,1966 & 0.000 & Valid \\
\hline Y5 & 0,600 & 0,1966 & 0.000 & Valid \\
\hline
\end{tabular}

Sumber: Hasil analisa peneliti melalui SPSS

Hasil pengamatan pada rTabel didapatkan nilai dari sample $(\mathrm{N})=100$
Tabel 4.

Hasil Uji reabilitas variable $X$ (Intensitas penggunaan smartphone) dan Y (Perilaku komunikasi)

Reliability Statistics

\begin{tabular}{|c|c|}
\hline $\begin{array}{c}\text { Cronbach's } \\
\text { Alpha }\end{array}$ & $\mathrm{N}$ of Items \\
\hline .74 & 3 \\
\hline \multicolumn{2}{|c|}{ Reliability Statistics } \\
\hline Cronbach's & \\
\hline Alpha & $\mathrm{N}$ of Items \\
\hline .683 & 5 \\
\hline
\end{tabular}

Dari hasil uji reabilitas didapatkan semua nilai dari hasil variable $\mathrm{x}$ dan $\mathrm{y}$ semuanya menghasilkan nilai alpa cronbach $>0,6$. Sehingga dapat disimpulkan bahwa 
semua instrument dalal penelitian ini reliable.

\begin{tabular}{|c|c|c|c|c|r|}
\hline \multicolumn{1}{|c|}{ Coefficients $^{\mathbf{a}}$} \\
& $\begin{array}{c}\text { Unstandardi } \\
\text { zed } \\
\text { Coefficients }\end{array}$ & $\begin{array}{r}\text { Standa } \\
\text { rdized } \\
\text { Coeffi } \\
\text { cients }\end{array}$ & & & \\
\cline { 2 - 5 } & B & $\begin{array}{c}\text { Std. } \\
\text { Error }\end{array}$ & Beta & $\mathrm{t}$ & Sig. \\
\hline $\begin{array}{c}\text { Model } \\
\text { (Cons } \\
\text { tant) } \\
\text { intens } \\
\text { itas } \\
\text { pengg } \\
\text { unaan }\end{array}$ & 3.075 & .923 & & 3.332 & .00 \\
& -.048 & .049 & -.097 & -.968 & .33 \\
\end{tabular}

\section{Uji normalitas data}

Tabel 5.

One sample kolmogrov - smirnov Test One-Sample Kolmogorov-Smirnov Test

\begin{tabular}{|c|c|c|}
\hline & & $\begin{array}{c}\text { Unstandard } \\
\text { ized } \\
\text { Residual }\end{array}$ \\
\hline 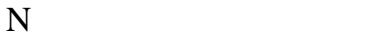 & & 100 \\
\hline Normal Parameters ${ }^{\mathrm{a}, \mathrm{b}}$ & $\begin{array}{l}\text { Mean } \\
\text { Std. } \\
\text { Devia } \\
\text { tion }\end{array}$ & $\begin{array}{r}.0000000 \\
2.78878326\end{array}$ \\
\hline Most Extreme Differences & $\begin{array}{l}\text { Absol } \\
\text { ute }\end{array}$ & .042 \\
\hline & $\begin{array}{l}\text { Positi } \\
\text { ve } \\
\text { Negat } \\
\text { ive }\end{array}$ & $\begin{array}{c}.032 \\
-.042\end{array}$ \\
\hline Test Statistic & & .042 \\
\hline Asymp. Sig. (2-tailed) & & $.200^{\mathrm{c}, \mathrm{d}}$ \\
\hline
\end{tabular}
a. Test distribution is Normal.
b. Calculated from data.
c. Lilliefors Significance Correction.

d. This is a lower bound of the true significance.

Berdasarkan uji normalitas diketahui nilai signifikansi $0,200>0,05$. Maka dapat disimpulkan bahwa variable Intensitas dan perilaku komunikasi berdistribusi normal, sehingga layak untuk digunakan sebagai bahan dalam tahap pengelolaan berikutnya. Setelah ini dilakukannya uji heterokedastitas (uji gleser)

\section{Uji Heterokedastitas (Uji Gleser) \\ Tabel 6. \\ Hasil uji heterokedastatis ( uji gleser )}

Dari hasil uji gleser, hasil signifikansi dari variable intensitas penggunaan ( $\mathrm{X}$ ) menunjukan sebesar 0,336 $>0,05$ artinya diatas dari standart signifikansi, sehingga dapat simpulkan bahwa tidak terjadi masalah heterokedastitas.

Kemudian setelah itu dilaksanakan analisis regresi, untuk mengetahui ada tidaknya pengaruh dari Intensitas Penggunaan Smartphone ( $\mathrm{X}$ ) Terhadap Perilaku Komunikasi ( Y ). 
Tabel 7.

Uji signifikansi pengaruh Intensitas Penggunaan Smartphone ( $X$ ) terhadap perilaku komunikasi ( Y )

ANOVA $^{\mathrm{a}}$

\begin{tabular}{|c|c|r|r|r|r|}
\hline Model & $\begin{array}{c}\text { Sum of } \\
\text { Squares }\end{array}$ & Df & $\begin{array}{r}\text { Mean } \\
\text { Square }\end{array}$ & F & Sig. \\
\hline Regre & 721.886 & 1 & $\begin{array}{r}721.88 \\
6\end{array}$ & 21.88 & $.000^{\mathrm{b}}$ \\
$\begin{array}{c}\text { Resi } \\
\text { dual } \\
\text { Total }\end{array}$ & 769.954 & 98 & 7.857 & & \\
\hline
\end{tabular}

a. Dependent Variable: perilaku komunikasi

b. Predictors: (Constant), intensitas penggunaan

Dari output tersebut diketahui nilai $\mathrm{F}$ hitung $=91,882$ dengan tingkat signifikansi $0,00<0,05$, maka model regresi dapat dipakai untuk memprediksi variable perilaku komunikasi atau dengan kata lain adanya pengaruh variable Intensitas Penggunaan Smartphone ( $\mathrm{X}$ ) terhadap Perilaku komunikasi ( Y ). Berdasarkan hasil tersebut selanjutnya dihitung persamaan regresi. Yang digunakan untuk melakukan prediksi seberapa tinggi nilai variable ( $\mathrm{X}$ ).

Tabel 8.

\section{Koefisien regresi pengaruh Intensitas penggunaan Smartphone trhadap perilaku komunikasi}

Berdasarkan tabel 7, diketahui nilai contans sebesar 1,732 sedangkan nilai intensitas penggunaan (b/ koefisien regresi) sebesar 0,777. Sehingga persamaan regresina dapat ditulis:

$\mathbf{Y}=\mathbf{a}+\mathbf{B x}$

$Y=1,732+0,777 X$
Persamaan tersebut dapat disimpulkan:

- Konstanta sebesar

1,732

Coefficients $^{\mathrm{a}}$

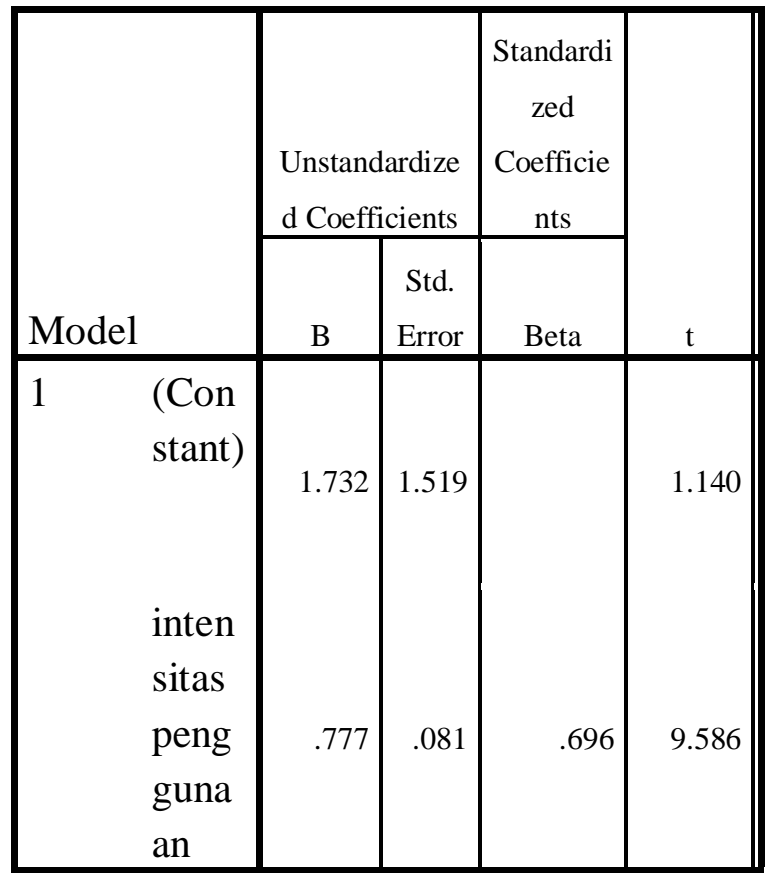

a. Dependent Variable: perilaku komunikasi mengandung arti bahwa nilai konsisten variable perilaku komunikasi sebesar 1,732

- Koefisien regresi X sebesar 0,777 menyatakan bahwa setiap penambahan $1 \%$ nilai intensitas penggunaan smartphone, maka nilai perilaku komunikasi bertambah sebesar 0,777. Koefisien regresi tersebut berilai positif, sehingga dapat dikatakan bahwa arah pengaruh variable $\mathrm{X}$ terhadap $\mathrm{Y}$ adalah positif.

Pengambilan keputusan dalam Uji regresi Sederhana:

- Berdasarkan nilai signifikansi : dari table Coefficents diperoleh nilai signifikansi sebesar $0,000<0,005$ 
sehingga dapat disimpulkan bahwa variable Intensitas Penggunaan Smartphone ( $\mathrm{X}$ ) berpengaruh terhadap variable perilaku komunikasi ( Y )

- Berdasarkan nilai $\mathrm{T}$ diketahui nilai tHitung sebesar 9,586>tTable 1,6602 sehingga dapat disimpulkan bahwa variable Intensitas Penggunaan Smartphone ( $X$ ) berpengaruh terhadap variable Perilaku Komunikasi ( Y )

\section{Koefisien Determinasi}

Analisis koefisien determinasi ini digunakan untuk mengetahui seberapa besar kekuatan hubungan antara pengaruh varibel ( $\mathrm{X}$ ) terhadap variable ( $\mathrm{Y}$ ). Adapun koefisien korelasi ${ }^{\circledR}$ yang didapatkan akan dilihat sberapa besar kekuatan hubungannya melalui tabel kriteria berikut:

\begin{tabular}{ll}
\hline Interval koefisien & $\begin{array}{l}\text { Tingkat } \\
\text { hubungan }\end{array}$ \\
\hline $\mathbf{0 , 0 0}-\mathbf{0 , 1 9 9}$ & Sangat rendah \\
\hline $\mathbf{0 , 2 0}-\mathbf{0 , 3 9 9 9}$ & Rendah \\
\hline $\mathbf{0 , 4 0}-\mathbf{0 , 5 9 9 9}$ & Sedang \\
\hline $\mathbf{0 , 6 0}-\mathbf{0 , 7 9 9}$ & Kuat \\
\hline $\mathbf{0 , 8 0}-\mathbf{1 , 0 0 0}$ & Sangat kuat \\
\hline
\end{tabular}

Sumber: (sugiono,2010)

Hasil korelasi digunakan untuk mengetahui seberapa kuat hubungan antara dua variable, mengetahui arah hubungan apakah positif atau negatif.

Tabel 9.

Uji korelasi

\section{Correlations}

\begin{tabular}{|c|c|c|}
\hline & $\begin{array}{c}\text { intensitas } \\
\text { pengguna } \\
\text { an }\end{array}$ & $\begin{array}{c}\text { perilaku } \\
\text { komunik } \\
\text { asi }\end{array}$ \\
\hline
\end{tabular}

\begin{tabular}{|c|c|c|c|}
\hline $\begin{array}{l}\text { intensitas } \\
\text { penggunaa } \\
\mathrm{n}\end{array}$ & $\begin{array}{l}\text { Pearson } \\
\text { Correlatio } \\
\mathrm{n} \\
\text { Sig. (2- } \\
\text { tailed) } \\
\mathrm{N} \\
\end{array}$ & . & $\begin{array}{r}.696^{* *} \\
.000 \\
100 \\
\end{array}$ \\
\hline $\begin{array}{l}\text { perilaku } \\
\text { komunika } \\
\text { si }\end{array}$ & $\begin{array}{l}\text { Pearson } \\
\text { Correlatio } \\
\mathrm{n} \\
\text { Sig. (2- } \\
\text { tailed) }\end{array}$ & $.696^{* *}$ & 1 \\
\hline & $\mathrm{N}$ & 100 & 100 \\
\hline
\end{tabular}

Tabel diatas diketahui bahwa besarnya nilai koefisien korelasi (r) intensitas penggunaan dengan nilai perilaku komunikasi sebesar 0,696>rTabel $100=$ 0,1662 taraf signifikansi $5 \%$, yang berarti ada korelas yang signifikan antara Intensitas Penggunaan Smartphone terhadap Perilaku komunikasi taruna Poltekip. Besarnya nilai probabilitas atau sig(2-tailed) untuk hubungan antar variable sebesar $0.000<$ 0.05. ini berarti bahwa ada korelasi yang signifikan antara dua variable.

Adapun koefisien korelasi Intensitas Pwnggunaan smartphone dengan perilaku komunikasi sebsesar 0,696 bertanda positif. Hal ini menunjukan pengertian bahwa semakin tinggi tingkat intensitas penggunaan smartphone maka akan meningkatkan perilaku komunikasi.

Koefisien determinasi r2 digunakan untk mengukur seberapa jauh kemampuan variable independen dalam menerangkan variable dependen. Dari table diatas meunjukan nilai $\mathrm{R}$ square/ koefisien 
determinasi sebesar 0,696. Yang menunjukan bahwa Intensitas Penggunaan Smartphone (X) dapat mempengaruhi kuat Perilaku Komunikasi (Y) dengan presentase sebesar 69\% sedangkan sisanya $31 \%$ dipengaruhi oleh variable lain yang tidak diukur/diteliti pada penelitian.

\section{PEMBAHASAN}

\section{Karakteristik responden}

Dari hasil penelitian diperoleh data yaitu pengguna smartphone didominasi oleh pria sebanyak $70 \%$. Hal ini dkarenakan jumlah Pria Taruna Politeknik Ilmu Pemasyarakatan lebih banyak dengan jumlah 786 dan lebih banyak dari jumlah wanita yaitu 215. Selain itu mayoritas responden menggunakan smartphone pada jam kosong perkuliahan, di sela - sela perkuliahan, dan setelah apel malam. Memang pada jam tersebut adalah waktu yang tepat digunakan untuk bermain gadget, seperti membuka jejaring sosial seperti Instagram, Whatsapp, Youtube dan sebagainya. Tetapi harus diperhatikan juga yang sudah ada pada dalam Peraturan Kehidupan Taruna (PERDUPTAR) mengenai Jam Malam yaitu pukul 22.00, dimana Taruna poltekip harus mematuhi adanya peraturan tersebut.

\section{Variable Intensitas Penggunaan Smartphone ( X )}

Dalam mengukur intensitas penggunaan smartphone, indikator yang digunakan yaitu Frekuensi dan Durasi. Dengan presentase sebesar $65 \%$. Sehingga dapat disimpulkan bahwa indikator yang terdapat pada variable Intensitas Penggunaan Smartphone termasuk kategori baik.

\section{Variable Perilaku Komunikasi (Y)}

Untuk mengukur perilaku komunikasi, peneliti menggunakan variabel perilaku komunikasi. Indikator yang terdapat pada variabel perilaku komunikasi yaitu kognitif, dan konatif. Dengan nilai rata-rata presentase sebesar $70 \%$, berdasarkan garis kontinum dapat disimpulkan bahwa indikator yang terdapat pada variabel perilaku komunikasi termasuk kategori baik.

\section{Pengaruh Intensitas Penggunaan Smartphone Terhadap Perilaku Komunikasi}

Analisis data membuktikan bahwa intensitas penggunaan smartphone berpengaruh terhadap perilaku komunikasi sebesar 69\%. Tanggapan responden menunjukkan bahwa mereka ratarata menggunakan smartphone dengan frekuensi dan durasi yang tinggi. Untuk sekedar membuka jejaring sosial dan berkomunikasi dengan teman, keluarga, senior - junior dan juga pembina yang ada di lingkungan Poltekip. Responden pun mengakui bahwa hal ini berpengaruh terhadap perilaku komunikasi mereka. Mereka mengakui dengan adanya Smartphone dapat meunjunjang kegiatan pola - pola Pengajaran, Pelatihan dan Pengasuhan yang terdapat di Poltekip dengan baik.

\section{KESIMPULAN}

Berdasarkan hasil penelitian pada bab sebelumnya, serta pembahasan mengenai pengaruh intensitas penggunaan smartphone terhadap perilaku komunikasi dapat di tarik simpulan sebagai berikut. 
1. Berdasarkan analisis, tanggapan responden terhadap intensitas penggunaan smartphone mencapai angka presentase $65 \%$. Hal tersebut menunjukan bahwa intensitas penggunaan smartphone di kalangan Taruna Poltekip termasuk dalam kategori tinggi. Dengan rata - rata kurang lebih selama 4 jam mereka menggunakan smartphone untuk berkomunikasi dan juga membuka konten yang terdapat di dalamnya.

2. Perilaku komunikasi pengguna mempunyai keyakinan bahwa penggunaan smartphone tersebut sangat baik. Dan mengakui sangat bermanfaat di lingkungan pendidikan kedinasan pada kampus Poltekip. Sehingga angka tanggapan responden terhadap perilaku komunikasi mencapai nilai 70\%. Hal tersebut menunjukan bahwa perilaku komunikasi termasuk dalam kategori baik.

3. Terdapat pengaruh antara variable independen terhadap variable dependen sebesar $69 \%$ yang telah diuji melalui uji koefisien determinasi. Artinya, intensitas penggunaan smartphone berpengaruh sebesar $69 \%$ terhadap perilaku komunikasi. Sementara itu sisanya sebesar $31 \%$ dapat dijelaskan oleh variable lain yang tidak diteliti.

\section{SARAN}

Bagi para pengguna smartphone khususnya Taruna, baik taruna tingkat I, tingkat II, tingkat III, dan juga tingkat IV diharapkan tidak menyalahgunakan penggunaan smartphone dan tidak menggunakan smartphone dengan frekuensi yang terlalu sering dan dengan durasi yang sangat lama. Hal itu dapat menggangu proses kegiatan anda sebagai Taruna dengan jadwal yang begitu teratur dan pada, selain itu dapat menjadi perilaku komunikasi yang buruk bagi pengguna smartphone itu.

Dengan adanya penelitian ini, saya mengharapkan kepada peneliti lainnya yang ingin membuat penelitian dengan topik yang sama agar mengkombinasikan dengan teori lain yang tidak digunakan dalam penelitian ini, serta variable lain yang tidak terdapat dalam penelitian ini.

\section{DAFTAR PUSTAKA}

[1] Musdalifah, M (2017), Pengaruh intensitas penggunaan smartphone terhadap perilaku sosial

[2] Rahmawati, Kurnia (2018). Pendidikan Karakter Taruna Sekolah tinggi Kedinasan. Tegal

[3] Anwar, Sanusi. (2011). Metode Penelitian Bisnis. Salemba Empat, Jakarta.

[4] Prasetyo, Bambang (2005). Metode penelitian kuantitaif. Rajawali pers, Jakarta

[5] A, W Gerungan. (1988). Psikologi Sosial. Jakarta: Eresco 